\section{Racial Income Inequality, Perceptions of Competition, and Negative Interracial Outcomes}

\author{
Jonathan Gordils' ${ }^{\prime} \oplus$, Nicolas Sommet ${ }^{2}$, Andrew J. Elliot', \\ and Jeremy P. Jamieson'
}

Social Psychological and

Personality Science

$1-14$

(c) The Author(s) 2019

Article reuse guidelines:

sagepub.com/journals-permissions DOI: 10.1 I 177/1948550619837003 journals.sagepub.com/home/spp

@SAGE

\begin{abstract}
There exists a racial income gap in America: Blacks earn $\sim 38 \%$ less than Whites, but little is known about its relation to interracial psychological outcomes. Toward this end, the present research examined associations between the Black-White income gap and perceptions of interracial competition and, subsequently, negative intergroup outcomes. Study I extracted data from a large, preexisting data set $(N=2,543)$ and provided initial support for the hypothesis that higher levels of racial income inequality are associated with increased perceptions of competition. Study 2 then recruited approximately equal numbers of White and Black participants $(N=\mathrm{I}, 73 \mathrm{I})$ and demonstrated that increases in racial income inequality predict increased perceptions of competition, discrimination, behavioral avoidance, and intergroup anxiety. Implications for theory development and public policy are discussed.
\end{abstract}

\title{
Keywords
}

racial income gap, inequality, competition

Historically, Black Americans have experienced worse outcomes than White Americans across numerous domains, and racial disparities persist in modern society (Bertrand \& Mullainathan, 2004; Knowles, Persico, \& Todd, 2001). In the educational system, a persistent achievement gap between Black and White students exists, with Blacks scoring lower than Whites on average (NCES, 2011; Vanneman, Hamilton, Anderson, \& Rahman, 2009). In vocational contexts, Blacks are more likely to be unemployed and exposed to occupational hazards compared to Whites (Williams \& Mohammed, 2009). Most pertinent to the present research, a notable racial income gap (RIGap) - the difference in average income between Blacks and Whites (Payne, 2017) - exists, such that Blacks earn $\sim 38 \%$ less than Whites (Gradín, 2014).

Research suggests myriad upstream antecedents of the RIGap, such as educational inequality, unemployment differences, and government policies (Jaret, Reid, \& Adelman, 2003; McKernan, Ratcliffe, Steuerle, \& Zhang, 2013; Shapiro $\&$ Kenty-Drane, 2005). In addition, a number of adverse societal consequences of racial income inequality have been documented, including racial disparities in health care and homeownership (McKernan et al., 2013; Phelan \& Link, 2015), as well as increases in violent crime and suicide (Blau \& Golden, 1986; Burr, Hartman, \& Matteson, 1999; Peterson $\&$ Krivo, 1993). Although research from the sociology, economics, and psychology literatures suggest adverse macro-level, societal consequences of the RIGap (e.g., Blau $\&$ Blau, 1982; Parker \& McCall, 1999), questions regarding the person-level, psychological effects of the RIGap have gone unexplored. In fact, no empirical research to date has examined how this disparity may influence psychological processes and outcomes. Toward this end, the present research tested perceptions of competition as a central psychological variable for addressing how the RIGap may impact interracial psychological outcomes, namely, perceived discrimination, behavioral avoidance, intergroup anxiety, and intergroup mistrust.

\section{The RIGap and Perceptions of Competition}

Although the influence of the RIGap on psychological outcomes has received no empirical attention to date, a large corpus of research links general income inequality to competition and posits competition as a proximal predictor of downstream psychological effects of inequality (Elgar, Gariépy, Torsheim,

\footnotetext{
'Department of Clinical and Social Sciences in Psychology, University of Rochester, Rochester, NY, USA

${ }^{2}$ University of Lausanne, Lausanne, Switzerland
}

\section{Corresponding Author:}

Jonathan Gordils, Department of Clinical and Social Sciences in Psychology, University of Rochester, 214 Meliora Hall, Rochester, NY I4627, USA.

Email: jonathan.gordils@rochester.edu 
\& Currie, 2017; Mishra, Hing, \& Lalumiere, 2015; Sommet, Elliot, Jamieson, \& Butera, 2018). Income inequality describes one's relative economic position as compared to relevant others. When no objective measure of "having enough" exists, one must rely on comparing oneself to others to determine what is sufficient to identify as "well-off" (Festinger, 1954; Fiske, 2010). Thus, social comparisons are central to inequality experiences (Payne, Brown-Iannuzzi, \& Hannay, 2017), and high levels of economic inequality make comparisons on income particularly salient (Cheung \& Lucas, 2016). Not surprisingly, general income inequality reinforces consumption norms, discourages reciprocity, engenders positional competition, and increases perceptions that others are competitive (Kawachi \& Subramanian, 2014; Sommet et al., 2018).

Social comparisons occur across multiple levels. People not only compare themselves to others, but comparisons manifest at the group level with regard to social categories (Brown, 1988; Major, 1994). In American society, race is a prominent category, making race-based income comparisons an inevitable reality, and the substantial income gap between Blacks and Whites is likely to make interracial comparisons particularly salient. Social comparison processes, particularly racial comparisons, typically impact psychological processes implicitly and with little effort (e.g., Gilbert, Giesler, \& Morris, 1995; Greenwald \& Banaji, 1995; Zell \& Krizan, 2014), but the processing of salient race-based information can also operate explicitly (Jost, Banaji, \& Nosek, 2004). Although people can have difficulty accurately reporting on income disparities in their environment (Norton \& Ariely, 2011), cues signaling economic stratification of racial groups (e.g., housing, apparel, and transportation), nonetheless, "get in people's heads" to impact psychological processes. Thus, just as general income inequality predicts perceptions of competition (Sommet et al., 2018), we posit that as racial income inequality increases in one's environment, so does the salience of interracial stratification and perceptions of interracial competition.

"Us versus them" thinking (Brewer, 2001) commonly emerges when groups feel threatened or deprived of important outcomes compared to others and seek to improve their relative social position (Mummendey, Kessler, Klink, \& Mielke, 1999; Ten-Velden, Beersma, \& De Dreu, 2009; Vanneman \& Pettigrew, 1972). However, perceptions of competition can also stem from the concerns of advantaged groups about losing social position (Anier, Guimond, \& Dambrun, 2016; Guimond \& Dambrun, 2002; Moscatelli, Albarello, Prati, \& Rubini, 2014). Taken together, the impact of the RIGap on perceived competition may manifest in Black and White individuals.

\section{Perceptions of Competition and Downstream Interracial Psychological Outcomes}

Classic research in social psychology has documented that competition between social groups can evoke negative intergroup psychological processes and outcomes (Sherif, Harvey, White, Hood, \& Sherif, 1961; Tajfel \& Turner, 1979). For instance, perceptions of competitiveness in target persons predict less warmth toward those targets (Fiske, Cuddy, Glick, $\& \mathrm{Xu}, 2002)$, and people discriminate against and avoid members of competing out-groups (Stephan \& Stephan, 2000). Further, perceiving out-group members as competitive increases intergroup anxiety and decreases prosociality toward outgroup members (Islam \& Hewstone, 1993; Wilder \& Shapiro, 1989). Research also shows that neurochemical responses to competition (e.g., elevated testosterone levels) decrease interpersonal trust (Bos, Terburg, \& van Honk, 2010; Carré, Baird-Rowe, \& Hariri, 2014). Thus, competition is a core psychological factor in determining how social groups respond to one another.

In the specific context of interracial group processes, perceptions of race-based competition have been shown to produce negative psychological outcomes. Notably, integrated threat theory posits that competition can arise from conflicting interests over limited resources such as money, houses, and jobs; in this context, resources are threatened by the outgroup, which in turn evokes prejudicial attitudes and discriminatory behaviors toward the competing out-group (Stephan \& Stephan, 2000). Moreover, perceived competition between racial groups promotes the avoidance of competing racial groups, feelings of anxiety, and mistrust of out-group members (Allport, 1954; Brewer \& Gaertner, 2001; Paolini, Hewstone, Cairns, \& Voci, 2004). In short, research from different theoretical perspectives across multiple domains indicates that competition can lead to negative psychological outcomes.

\section{The Present Research}

We hypothesized that the income gap between Black and White Americans would predict perceptions of competition between the two groups, which may then impact negative interracial psychological outcomes. Two studies were conducted to test these hypotheses. Importantly, the RIGap was measured objectively at the local (ZIP code) level because its effects were expected to be most impactful where daily life is lived. Thus, supportive data would link an objective, macro-level economic indicator to person-level psychological processes and outcomes in the context of a critical societal problem-relations between Blacks and Whites.

Study 1 capitalized on an existing data set $(N=2,523)$ and tested the hypothesis that the RIGap positively predicts perceived general competition (Hypothesis 1). Study 2 built directly on Study 1 using new data from roughly equal numbers of Black and White participants to test the hypotheses that the RIGap predicts perceptions of interracial competition (competition between Blacks and Whites; Hypothesis 2) and that perceptions of interracial competition predicts perceptions of four important race-based psychological outcomes: perceived discrimination, behavioral avoidance, intergroup anxiety, and interracial mistrust (Hypothesis 3). Moreover, we hypothesized that the influence of racial income inequality on these psychological outcomes would manifest indirectly through increasing perceptions of interracial competition (Hypothesis 4). 
For each study, we controlled for pertinent sociodemographic and area-based variables that were identified a priori (Wilkinson \& Pickett, 2006). The sample size for Study 2 was determined a priori using power analysis (Study 1 utilized an existing data set). All analyses were planned a priori, and all data exclusions and variables analyzed are reported.

\section{Study I: RIGap and Perceived Competition}

Study 1 tested the association between the RIGap and perceived competition (Hypothesis 1). U.S. residents provided their ZIP code before reporting the extent to which they perceived competition in their town or city. Participants also reported demographic information including race.

\section{Method}

\section{Sample and Procedures}

Study 1 compiled the sample from an existing data set (Sommet et al., 2018): The RIGap was not computed, analyzed, or discussed in the work from which these data were culled.

\section{Participants}

The total sample included 2,543 U.S. residents; 262 participants not self-identifying as White nor Black/African American and 106 participants for whom the RIGap values were unavailable were excluded a priori from analyses, leaving a sample of $N=2,175$ (1,533 females, 642 males; 2,040 White, 135 Black/African American; $M_{\text {age }}=43.92, S D_{\text {age }}=15.30$, age range $=15-83)$. Participants were recruited using ResearchMatch $(n=1,495)$ and Amazon's Mechanical Turk (MTurk; $n=680$ ). MTurk participants were compensated US $\$ 0.40$ for participation; ResearchMatch participants received no monetary compensation (as is standard).

Local economic indicators were collected using the 2014 American Community Survey's 5-year estimates (the most recent estimates available during collection). These data are publicly available from the U.S. Census Bureau (see http://fact finder.census.gov/).

\section{Measures}

See Table 1 for descriptive statistics and intercorrelations. All measures used a 7-point scale $(1=$ not at all, $4=$ somewhat, $7=$ completely). See Appendix A for items.

RIGap. The RIGap was calculated using ZIP Code Tabulation Area (ZCTA)-based average income data provided by the American Community Survey. A gap score was calculated using the income difference between Whites and Blacks in a given ZIP code area. Higher values correspond to Whites having more income than Blacks.

Perceived competition. Murayama and Elliot's (2012) 5-item perceived competition scale was adapted. Example items include
Table I. Study I: Descriptive Statistics and Intercorrelations for the Racial Income Gap and Perceived Competition

\begin{tabular}{|c|c|c|c|c|c|}
\hline \multirow[b]{2}{*}{ Variable } & \multicolumn{3}{|c|}{ Descriptive Statistics } & \multicolumn{2}{|c|}{$\begin{array}{c}\text { Pairwise } \\
\text { Intercorrelations }\end{array}$} \\
\hline & $\alpha$ & $M$ & $S D$ & 1 & 2 \\
\hline Racial income gap & - & $\$ 12,828.30$ & $\$ 14,265.60$ & - & \\
\hline $\begin{array}{l}\text { Perceived } \\
\text { competition }\end{array}$ & .92 & 3.90 & 1.50 & $.15^{* * *}$ & - \\
\hline
\end{tabular}

Note. $S D=$ standard deviation.

$*_{p}<.05$. **p $<.01$. ***p $<.001$.

$\dagger^{\dagger} p<.10$.

"In my town/city, it seems that people are competing with each other" $(\alpha=.92)$.

\section{Results}

\section{Main Analyses: RIGap and Perceived Competition}

Design effect, general income inequality, and control variables. Single-level rather than two-level regression analysis was used because the design effect indicated the incidence of ZIP code clustering was negligible (see Supplementary Material). We controlled for ZIP code Gini, which indexes general income inequality, to distinguish the effect of the RIGap from that of general income inequality. In addition, we controlled for six individual-level sociodemographic variables: (1) race (Black $=0$, White =1), (2) sex (female $=0$, male =1), (3) age, (4) employment status (working for payment or profit $=1$, all else $=0$ ), (5) income, and (6) education (2-year college degree or higher $=1$, some college or lower $=0$ ); and four area-based composition variables identified by Wilkinson and Pickett (2006): (1) size (i.e., number of inhabitants), (2) employment rate, (3) absolute level of poverty, and (4) percent without a high school education.

RIGap on perceived competition. Hierarchical multiple regression was used to examine associations between the RIGap and perceived competition (see Table 2). Consistent with Hypothesis 1 , in Step 1, the RIGap predicted perceived competition, $\beta=$ $.15[.10, .19], p<.001$. This relation remained significant after including all demographic variables in Step $2, \beta=.06[.02$, $.11], p<.01$.

Whites also perceived more competition, in general, than Blacks, $\beta=.06[.02, .10], p=.007$ (see Table 2). ${ }^{1}$

\section{Discussion}

As predicted, the RIGap positively predicted perceived competition. This finding is consistent with the idea that race-based income inequality increases the salience of economic stratification, establishing a perception that the social environment is competitive. Although analyses of the RIGap on perceived competitiveness yielded supportive results, the data were not originally designed to examine racial differences. Furthermore, 
Table 2. Study I: Coefficient Estimates of the Racial Income Gap on Perceived Competition at the ZIP Code Level.

\begin{tabular}{|c|c|c|c|c|c|c|c|}
\hline \multirow{3}{*}{$\begin{array}{l}\text { Variable } \\
\text { Racial income gap }\end{array}$} & \multicolumn{3}{|c|}{ Step I } & \multicolumn{4}{|c|}{ Step 2} \\
\hline & \multirow{2}{*}{$\frac{\beta}{.15^{* * *}}$} & \multirow{2}{*}{$\begin{array}{l}S E \\
.02\end{array}$} & $95 \% \mathrm{Cl}$ & \multirow{2}{*}{$\frac{\beta}{.06 * *}$} & \multirow{2}{*}{$\begin{array}{l}S E \\
.02\end{array}$} & \multicolumn{2}{|c|}{$95 \% \mathrm{Cl}$} \\
\hline & & & .10 .19 & & & .02 & .11 \\
\hline $\begin{array}{l}\text { Race (Blacks vs. } \\
\text { Whites) }\end{array}$ & & & & $.06 * *$ & .02 & .02 & .10 \\
\hline $\begin{array}{l}\text { Sex (men vs. } \\
\text { women) }\end{array}$ & & & & .01 & .02 & -.03 & .05 \\
\hline Age & & & & $-.08 * * *$ & .02 & -.13 & -.04 \\
\hline $\begin{array}{l}\text { Employment } \\
\text { status }\end{array}$ & & & & $-.05^{*}$ & .02 & -.09 & -.004 \\
\hline Income & & & & $-.08 * * *$ & .02 & -.13 & -.03 \\
\hline Education & & & & .01 & .02 & -.03 & .05 \\
\hline Population & & & & $.07 * *$ & .02 & .03 & .11 \\
\hline Unemployment & & & & $.12 * * *$ & .03 & .07 & .17 \\
\hline Poverty rate & & & & -.01 & .03 & -.07 & .05 \\
\hline Education level & & & & .02 & .02 & -.02 & .07 \\
\hline $\begin{array}{l}\text { ZIP-based Gini } \\
\text { index }\end{array}$ & & & & $.17 * * *$ & .03 & .12 & .23 \\
\hline
\end{tabular}

Note. $S E=$ standard error; $\mathrm{Cl}=$ confidence interval.

$*_{p}<.05$. $* * p<.01$. $* * * p<.001$.

Study 1 examined general perceptions of competition, not more precise perceptions of interracial competition. Thus, in Study 2, we recruited a large sample with an equal distribution of White and Black participants and examined associations among RIGap, perceived Black-White competition, and interracial psychological outcomes.

We predicted that experiencing racial income inequality (i.e., a large RIGap) engenders perceptions of interracial competition because racial income inequality not only informs one's relative social position in broader society but also highlights race and intergroup differences on income in one's immediate social environment. In turn, these perceptions of interracial competition were hypothesized to influence perceptions of discrimination, behavioral avoidance, intergroup anxiety, and interracial mistrust.

\section{Study 2}

Study 2 examined the relations between the RIGap, perceived interracial competition, and several well-known psychological outcomes related to race and inequality. We first tested the association between the RIGap and perceived interracial competition (Hypothesis 2). Then, we tested the relation between the RIGap and perceptions of four race-based psychological outcomes: perceived discrimination, behavioral avoidance, intergroup anxiety, and interracial mistrust (Hypothesis 3). Finally, we tested the indirect effect of the RIGap on the interracial outcomes of interest via perceptions of interracial competition (Hypothesis 4).

Additionally, exploratory analyses examined effects of participant race. We expected to replicate known effects such as heightened perceptions of discrimination and mistrust by
Blacks (Brewer \& Gaertner, 2001; Nunnally, 2012; Williams, Yu, Jackson, \& Anderson, 1997). However, we were agnostic as to influence of race on interracial competition as a function of increased RIGap (Bobo \& Hutchings, 1996; Jacobs \& Wood, 1999; Oliver \& Mendelberg, 2000).

\section{Method}

\section{Sample and Procedure}

An a priori power analysis revealed that 787 Black and 787 White participants $(N=1,574)$ were needed to detect a small-sized total effect of the RIGap $\left(f^{2}=.01\right)$ within a 12 predictor model, given a targeted power of .80 . This target sample size was also sufficient to detect a small-sized indirect effect of the RIGap via perceived racial competition (with $\beta_{X \rightarrow Y}=$ $\beta_{X \rightarrow \mathrm{Me}}=\beta_{\mathrm{Me} \rightarrow Y}=.10$ ) with a power of .81 (calculated using Perugini, Gallucci, \& Costantini's, 2018, approach). ${ }^{2}$

MTurk was used to collect the data and followed the same approach as Study 1.

\section{Participants}

The total sample included 1,731 individuals; 86 participants for whom the RIGap or ZIP code Gini were unavailable were excluded a priori from analyses. One influential case (i.e., having an extreme Cook's distance) was also removed, ${ }^{3}$ leaving a sample of $N=1,644$ participants ( 988 females, 656 males, 782 White, 862 Black/African American; $M_{\text {age }}=35.25, S D_{\text {age }}=$ 11.43 , age range $=18-73$ ).

\section{Measures}

See Table 3 for descriptive statistics and intercorrelations. See Appendix B for items.

RIGap. The RIGap was assessed using the same measure as Study 1, except we used the most recent estimates available at the time of collection (2015 American Community Survey's 5 -year estimates).

Perceived racial income inequality. A 3-item scale measured the perceived RIGap. For example, "In my town/city, the income disparity between Blacks and Whites is large" $(1=$ not at all and $7=$ completely; $\alpha=.79$ ).

Perceived racial competition. Murayama and Elliot's (2012) 5 -item Perceived Competition Scale was adapted to fit the race-based focus of the study (e.g., "In my town/city, it seems that Blacks and Whites are competing against each other"; $1=$ not at all and $7=$ completely $\alpha=.92$ ).

\section{Interracial outcomes}

Perceived discrimination. The 9-item Everyday Discrimination Scale (Clark, Coleman, \& Novak, 2004) was adapted. Original instructions read: "In your day-to-day life how often have any of the following things happened to you because of your race?," 
Table 3. Study 2: Descriptive Statistics and Intercorrelations for the Racial Income Gap, Perceived Racial Income Inequality, Perceived Racial Competition, and the Race-Based Psychological Outcomes.

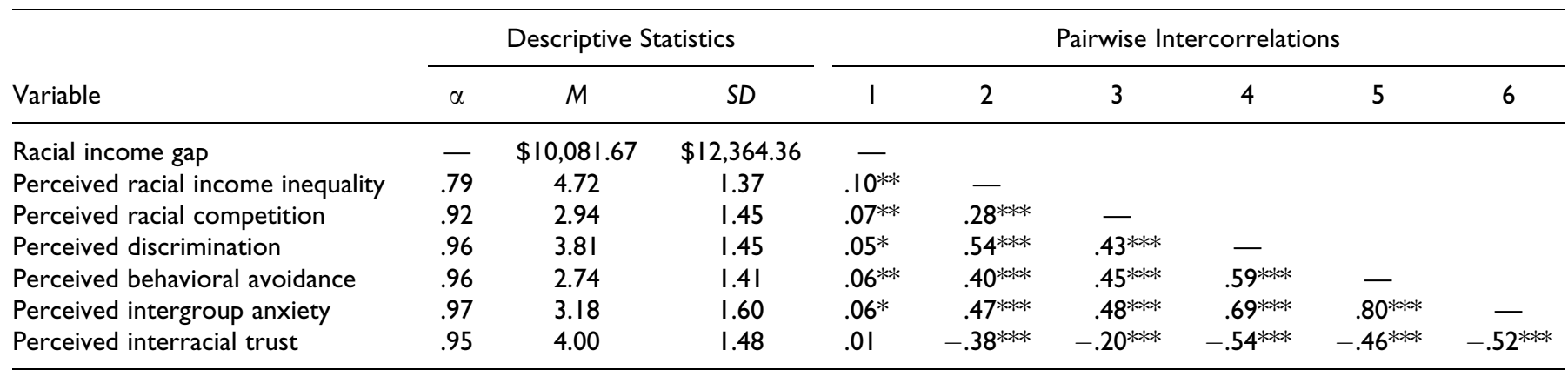

Note. $S D=$ standard deviation.

$* p<.05$. $* * p<.01$. $* * * p<.001$.

Table 4. Study 2: Standardized Coefficient Estimates of the Racial Income Gap on Perceived Racial Competition at the ZIP Code Level.

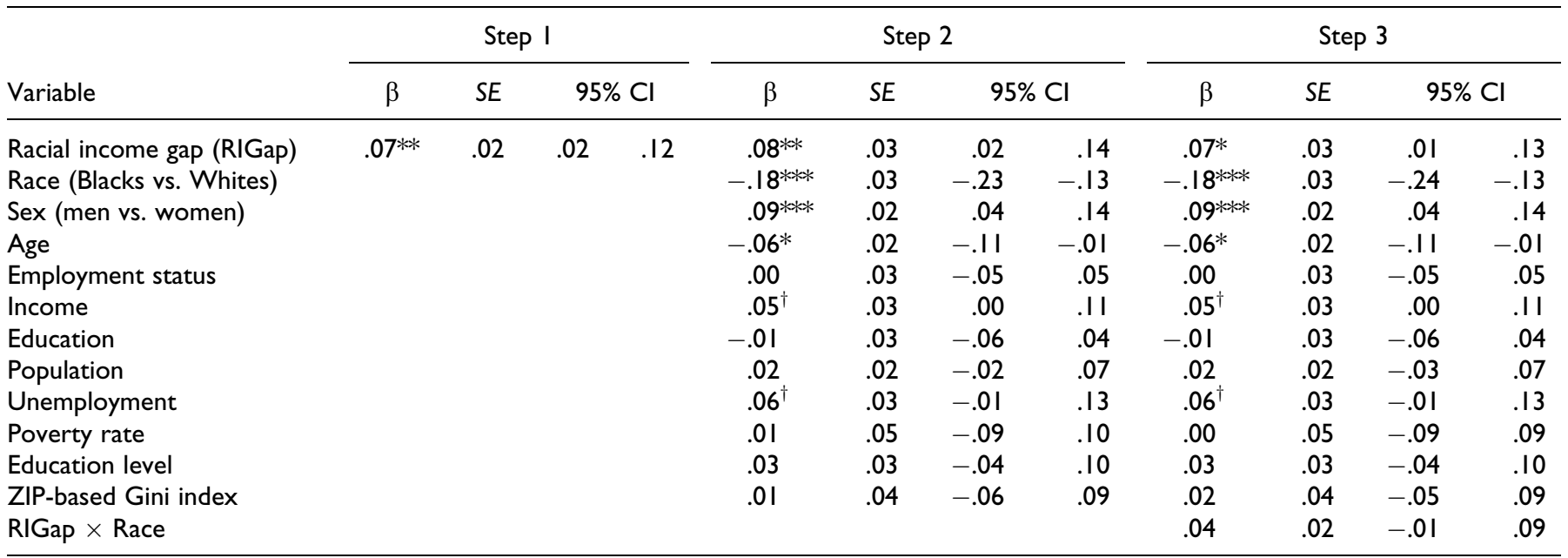

Note. $\mathrm{SE}=$ standard error; $\mathrm{Cl}=$ confidence interval.

$* p<.05$. $* * p<.01$. $* * * p<.001$.

${ }^{\dagger} p<.10$.

the adapted scale read: "In your town/city, how often do the following things happen to people because of their race?" A sample event included: "Being treated with less courtesy than others" ( $1=$ never and $7=$ frequently; $\alpha=.96)$.

Perceived behavioral avoidance. Lackey's (2012) 11-item Behavioral Avoidance Scale was adapted (e.g., "In my town/ city, Black and White people try to avoid having conversations with each other"; 1 = strongly disagree and 7 = strongly agree; $\alpha=.96)$.

Perceived intergroup anxiety. Four items were adapted from Amodio's (2009) state affect measure (e.g., "In my town/city, Black and White people feel nervous about interacting with each other"; 1 = strongly disagree and 7 = strongly agree; $\alpha=.97)$.

Perceived interracial mistrust. Four items were adapted from Yamagishi and Yamagishi's (1994) General Trust Scale (e.g., "In my town/city, Black and White people view each other as trustworthy"; $1=$ not at all and $7=$ completely; $\alpha=.95$ ).

\section{Results}

\section{Preliminary Analysis: Actual and Perceived Racial Income Inequality Correlation}

The RIGap was positively correlated with perceived racial income inequality, $r=.10, p<.001$.

\section{Main Analyses}

Design effect and control variables. As in Study 1, single regression analysis was used as the impact of ZIP code clustering was negligible (see Supplementary Material), and the same control variables were used.

RIGap and perceived racial competition. Results are presented in Table 4. As in Study 1, hierarchical multiple regression was used to examine associations between the RIGap and perceived racial competition ( $a$ path). 
Social Psychological and Personality Science $X X(X)$

Consistent with Hypothesis 2, the RIGap positively predicted perceived racial competition in Step $1, \beta=.07$ [.02, $.12], p=.006$, and remained significant after including the control variables in Step $2, \beta=.08[.02, .14], p=.005$.

RIGap and interracial outcomes. Results are presented in Table 5. The same hierarchical multiple regression approach used above was used to examine the relation between the RIGap and each outcome variable ( $c$ paths).

Consistent with Hypothesis 3, in Step 1, the RIGap was a positive predictor of perceived discrimination, $\beta=.05[.005, .10]$, $p=.031$; behavioral avoidance, $\beta=.06[.02, .11], p=.009$; and intergroup anxiety, $\beta=.06[.01, .12], p=.010$, but not perceived interracial mistrust, $\beta=.01[-.04, .06], p=.694$. In Step 2, the effects remained significant after including control variables for perceived discrimination, $\beta=.06[.01, .12], p=.022$, and perceived intergroup anxiety, $\beta=.06[.00, .12], p=.044$.

Perceived racial competition and interracial outcomes. Results are presented in Table 6. First, hierarchical multiple regressions were conducted to examine the associations between perceived racial competition and each outcome variable controlling for the RIGap ( $b$ paths).

Consistent with Hypothesis 3, while controlling for the RIGap in Step 1, perceived racial competition predicted perceptions of discrimination, $\beta=.43[.39, .48], p<.001$; behavioral avoidance, $\beta=.45[.41, .50], p<.001$; intergroup anxiety, $\beta=.48[.44, .52], p<.001$; and interracial mistrust, $\beta=-.20[-.25,-.15], p<.001$. In Step 2, associations remained significant after including control variables (perceived discrimination: $\beta=.39[.34, .43], p<.001$; perceived behavioral avoidance: $\beta=.44[.39, .48], p<.001$; perceived intergroup anxiety: $\beta=.46[.42, .51], p<.001$; and perceived interracial mistrust: $\beta=-.15[-.20,-.10], p<.001)$.

Indirect effects. To test whether the RIGap predicted the interracial psychological outcomes via changes in perceptions of racial competition ( $a \times b$ path), we used indirect effect procedures with Model 4 of the SPSS macro PROCESS, Version 2.15, using the percentile bootstrap method (100,000 resamples) for each of the outcome variables while controlling for the Gini index and the same 10 sociodemographic variables as used in our previous analyses (Hayes, 2013; Yzerbyt, Muller, Batailler, \& Judd, 2018).

See Figure 1(A-D) for a summary of the results. Consistent with Hypothesis 4, perceived racial competition mediated the association between the RIGap and perceived discrimination, indirect effect $=.03[.01, .05]$ (Figure 1A); behavioral avoidance, indirect effect $=.04[.01, .06]$ (Figure 1B); and perceived intergroup anxiety, indirect effect $=.04,[.01, .06]$ (Figure 1C). Although we observed no total effect of the RIGap on interracial mistrust, the indirect effect of the RIGap via perceived racial competition on interracial mistrust was significant, indirect effect $=-.01[-.02,-.004]$ (Figure 1D).

Exploratory analyses-Race and RIGap $\times$ Race interaction. We additionally tested for the main effect of race and the interaction between RIGap and race on perceived racial competition and our four interracial outcomes (i.e., $2 \times 10$ new tests; see Tables 4 and 5 for results). We applied the sequential Bonferroni procedure as a correction for multiple comparison (Cramer et al., 2016): for the smallest $p$ value, the adjusted $\alpha$ level was $\alpha_{\text {adj }}=.05 / 10=.005$; for the second smallest $p$ value, it was $\alpha_{\text {adj }}=.05 / 9=.006$; and so on.

Race predicted perceived racial competition, $\beta=-.18[-.23$, $-.13], p<.001$; Blacks perceived greater interracial competition than Whites. Moreover, race predicted each of the four interracial outcomes (discrimination: $\beta=-.21[-.26,-.16], p<.001$; behavioral avoidance: $\beta=-.09[-.14,-.04], p=.001$; intergroup anxiety: $\beta=-.09[-.14,-.04], p<.001$; and mistrust: $\beta=.20[.15, .25], p<.001)$. Blacks perceived more discrimination, behavioral avoidance, intergroup anxiety, and interracial mistrust compared to Whites. None of the RIGap $\times$ Race interactions were significant at the adjusted $\alpha$ level. ${ }^{4}$

Exploratory analyses-Race and Perceived Racial Competition $\times$ Race interaction. When perceived racial competition was included, race remained significant only for perceived discrimination, $\beta=-.14[-.18,-.09], p<.001$, and interracial mistrust, $\beta=.17[.12, .22], p<.001$. The Perceived Racial Competition $\times$ Race interaction was not significant for any of the outcomes (see Table 6 for results).

\section{Discussion}

Supporting hypotheses and extending findings from Study 1, the RIGap positively predicted perceived interracial competition. This finding is consistent with the idea that as the RIGap increases at the local level, race-based economic stratification becomes more salient, thus engendering perceptions of competition between racial groups in one's immediate social environment. Moreover, the objective RIGap predicted psychological outcomes. Increases in the income gap predicted increased perceptions of discrimination, behavioral avoidance, and intergroup anxiety. Finally, indirect effect analyses suggest that perceptions of interracial competition may emerge as a mechanism for how racial income inequality feeds forward to impact interracial outcomes, though this causal link needs to be tested in future experimental research.

Exploratory analyses suggested that participant race impacted perceptions of interracial competition-Blacks perceived more interracial competition than Whites - and the outcome variables. Compared to Whites, Blacks perceived more discrimination, intergroup anxiety, behavioral avoidance, and interracial mistrust, which are consistent with the extant literature (Lackey, 2012; Nunnally, 2012; Stephan et al., 2002).

\section{General Discussion}

This research tested associations between the RIGap, perceptions of competition, and interracial psychological outcomes. Study 1 found that the RIGap predicted perceptions of general competition. Building on these findings, Study 2 found that the 

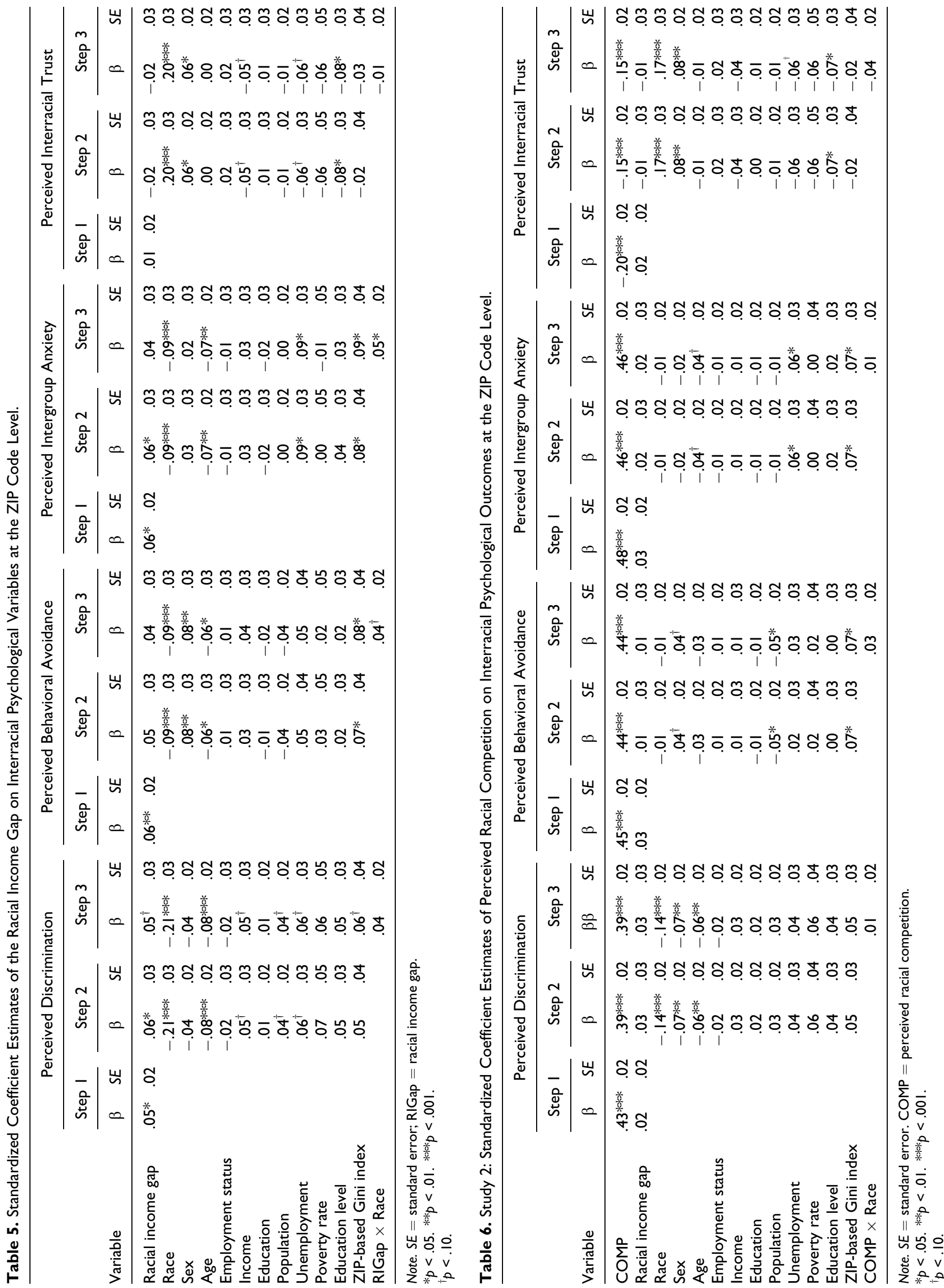


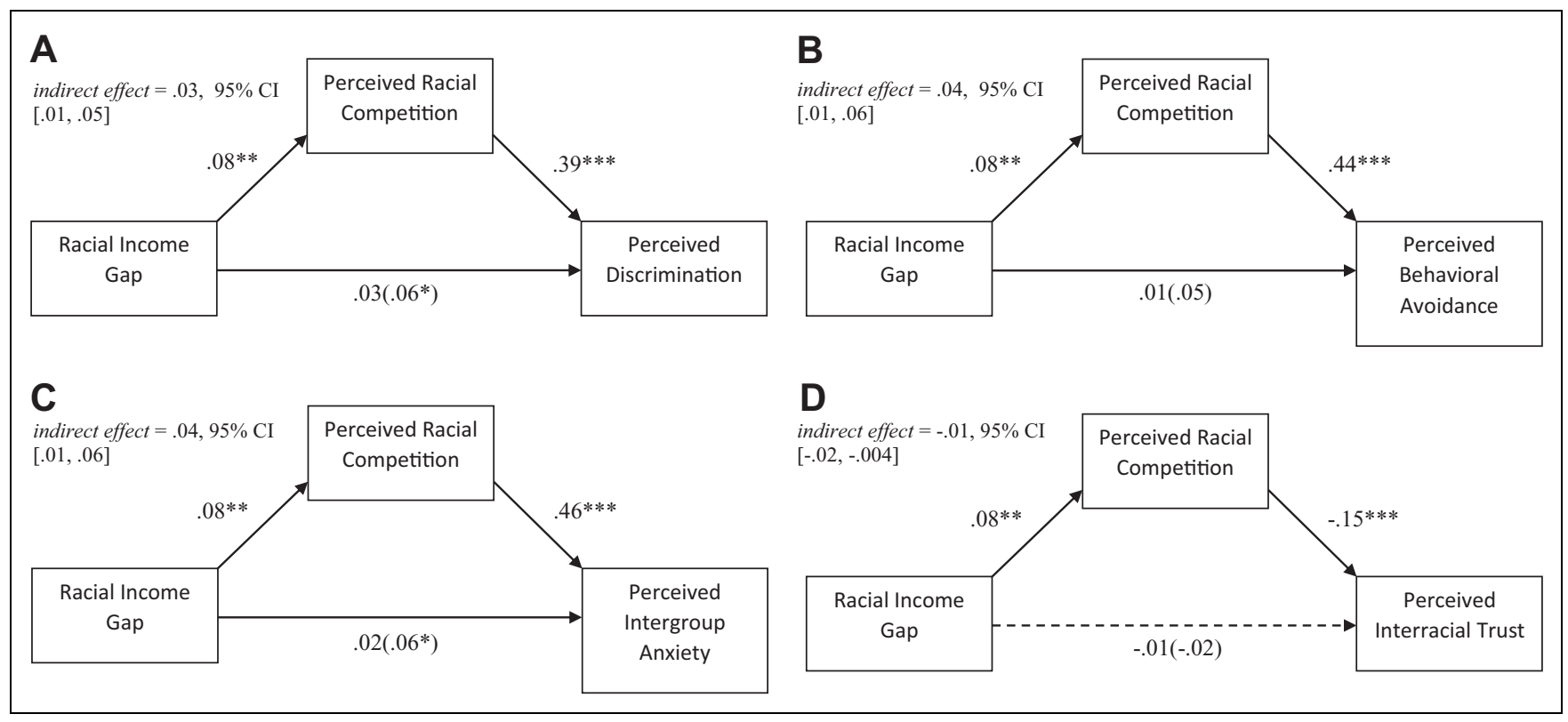

Figure I. Examining the indirect role of perceived racial competition on the association between racial income gap and (A) perceived discrimination, (B) perceived behavioral avoidance, $(C)$ perceived intergroup anxiety, and (D) perceived interracial trust. For the ease of interpretation, standardized $\beta$ s are depicted; parentheses separate the direct effect ( $c^{\prime}$ path; outside) from the total effect (c path; inside); dashed lines indicated nonsignificance; $*_{p}<.05$. $*_{p}<.01$. ***p $<.00 \mathrm{I}$.

RIGap directly predicted both perceptions of interracial competition and psychological outcomes and indirectly predicted the same psychological outcomes via perceptions of interracial competition.

Taken together, the data suggest that living in areas with high racial income inequality may potentially increase perceptions of competition between racial groups, which has the potential to lead to negative outcomes. That is, in such areas, Blacks and Whites may not only be distant from each other with respect to income but also psychologically and socially distant: They may perceive cross-race encounters as more anxious, perceive more discrimination, and believe social groups avoid each other. Accordingly, as the income distance between Blacks and Whites grows, the psychological distance grows in kind, which can maintain societal-level racial disparities, perpetuating the RIGap, in a recursive feedback loop.

\section{Implications for Theory Development and Public Policy}

The four psychological outcome variables examined here can contribute to and maintain societal-level racial disparities (Gibbons, Gerrard, Cleveland, Wills, \& Brody, 2004; Kessler, Mickelson, \& Williams, 1999; Pascoe \& Smart Richman, 2009). For instance, African Americans who perceive more discrimination are more likely to engage in substance use (Gibbons et al., 2004), and perceptions of being discriminated against by health-care providers predict lower quality of health care and worse health outcomes (Burgess, Ding, Hargreaves, Van Ryn, \& Phelan, 2008; Lee, Ayers, \& Kronenfeld, 2009). Thus, perceived discrimination can maintain racial health disparities (Dressler, Oths, \& Gravlee, 2005; Mays, Cochran, \& Barnes, 2007; Williams \& Mohammed, 2009).
Increases in behavioral avoidance are associated with residential segregation (Emerson, Chai, \& Yancey, 2001; Quillian, 2002), and this link is particularly strong for Whites avoiding Blacks (Crowder, 2001). Subsequently, residential segregation in the United States is linked to racial disparities, such as poor educational environments and outcomes for Black students, and worse health outcomes for Blacks in general relative to Whites (Shapiro, Meschede, \& Osoro, 2013; Williams \& Collins, 2001). The current research suggests that racial income inequality may have the potential to contribute to problems associated with racial segregation (White, Haas, \& Williams, 2012).

Perceived intergroup anxiety has myriad negative psychological, behavioral, and health consequences (Mendes, Gray, Mendoza-Denton, Major, \& Epel, 2007; Page-Gould, Mendoza-Denton, \& Tropp, 2008; Trawalter, Richeson, \& Shelton, 2009). Broadly, anxiety is characterized by perceptions of uncertainty (Calvo \& Castillo, 2001), and physiological and attentional processes associated with anxiety impair performance and bias attention for negative cues. More long-term, anxiety responses are associated with cognitive decline and cardiovascular disease (Jamieson, Nock, \& Mendes, 2012; Jefferson et al., 2010; McEwen, 1998). This research informs how a social-situational factor, racial income inequality, may impact individual-level affective responses (for a review, see Jamieson, Hangen, Lee, \& Yeager, 2018).

\section{Limitations and Future Directions}

Limitations should be considered when interpreting these findings. First, all findings are correlational. Thus, caution should be exercised when making causal inferences from the reported indirect effect models. Notably, an important avenue for future 
research is to experimentally manipulate perceptions of interracial competition to elucidate causal effects of this hypothesized mechanism on psychological outcomes.

Moreover, it should be noted that while the RIGap effect is consistent across studies, the size of the effect is arguably quite small. However, small, but consistent, effects can be important for advancing theory and application (Prentice \& Miller, 1992; Rosenthal, Rosnow, \& Rubin, 2000) and have been shown to have paramount importance for downstream outcomes (Yeager, Dahl, \& Dweck, 2018).

Another limitation is the focus on perceived psychological processes and outcomes in both studies. That is, these data do not allow for definitive conclusions regarding behavioral or societal-level outcomes such as health behaviors (e.g., substance abuse or compulsive gambling) or discrimination. As such, one avenue of future research is to extend this research by linking psychological processes to more downstream objective outcomes. For example, past research suggests that general income inequality promotes unlawful or criminal behavior (Pickett \& Wilkinson, 2015).

Additionally, this research focused on the income gap between Whites and Blacks, not the wealth gap (Shapiro et al., 2013). Although income and wealth are correlated (Diaz-Gimenez, Quadrini, \& Ríos-Rull, 1997), income is more variable within a lifetime, whereas wealth is transmitted across generations. Although this research did not examine wealth, a similar pattern of results would be expected to emerge as a function of the racial wealth gap. Moreover, although we focused on a ZIP code level of analysis, the more local the lens, the stronger the associations between predictors and outcomes (Lochner, Kawachi, \& Kennedy, 1999; Sommet et al., 2018). Thus, future work might consider using an even more local lens (e.g., census tract) to elucidate the impact of racial income inequality on the psychological processes demonstrated here.

Another important direction for future research is to examine moderating variables. For instance, mind-sets and beliefs about income mobility and perceptions of the legitimacy of inequality would likely moderate the effects of RIGaps on psychological processes such as perceptions of competition. For instance, a belief that income mobility is fixed breeds intolerance of general income inequality (Shariff, Wiwad, \& Aknin, 2016), and people who perceive general income inequality as more legitimate are less negatively impacted by the experience of inequality (Schneider, 2012). Understanding the roles of these and other moderators will expand our understanding of how RIGaps influence psychological processes and downstream outcomes.

\section{Conclusion}

This research documented the impact of the RIGap on perceived competition and interracial psychological outcomes. This work is integrative in linking an objective, macro-level economic contextual factor to individual-level psychological processes, and it does so in a domain of utmost importancerace relations in America. The income gap between Blacks and
Whites in the United States is large and enduring. As such, it is paramount to understand how racial disparities impact individuals so as to best direct efforts and resources to attenuate potentially negative impacts of RIGaps.

\section{Appendix A}

\section{Scales}

Perceived competitiveness. Think about the town/city you live in. Please indicate how much you agree with each of the following statements:

(1) In my town/city, it seems that I am competing with others.

(2) In my town/city, people seem to value competition.

(3) In my town/city, it seems that people are competing with each other.

(4) In my town/city, people seem to share the feeling that competing with each other is important.

(5) In my town/city, I feel that I am being compared with others.

Seven-point scale $(1=$ not at all, $4=$ somewhat , and $7=$ completely).

\section{Appendix B}

\section{Scales}

Perceived racial income inequality. Think about the town/city you live in. Please indicate how much you agree with each of the following statements:

(1) In my town/city, there is a huge gap between Blacks and Whites.

(2) In my town/city, those in the top $1 \%$ of income earners are more likely to be White than Black.

(3) In my town/city, the income disparity between Blacks and Whites is large.

Seven-point scale $(1=$ not at all, $4=$ somewhat , and $7=$ completely).

Perceived racial competitiveness. Think about the town/city you live in. Please indicate how much you agree with each of the following statements:

(1) In my town/city, Blacks and Whites seem to value competition with each other.

(2) In my town/city, it seems that Blacks and Whites are competing with each other.

(3) In my town/city, Blacks and Whites seem to share the feeling that competing with each other is important.

(4) In my town/city, it seems that Blacks are competing with Whites and Whites are competing with Blacks.

(5) In my town/city, I feel that Blacks and Whites are being compared with one another. 
Seven-point scale $(1=$ not at all, $4=$ somewhat, and $7=$ completely).

Perceived discrimination. In your town/city, how often do the following things happen to people because of their race?

(1) Being treated with less courtesy than others.

(2) Being treated with less respect than others.

(3) Receiving poorer service than others in restaurants or stores.

(4) People acting as if he/she is not smart.

(5) People acting as if they are afraid of him or her.

(6) Others feeling they are better than him/her.

(7) Others thinking that he or she is dishonest.

(8) Being called names or insulted.

(9) Being threatened or harassed.

Seven-point scale $(1=$ never, $4=$ sometimes, and 7 = frequently).

Perceived behavioral avoidance. Rate how much you agree with each statement on a scale from 1 (strongly disagree) to 7 (strongly agree).

(1) In my town/city, Black and White people avoid having conversations with each other.

(2) In my town/city, Black and White people avoid having friendships with each other.

(3) In my town/city, Black and White people avoid spending leisure time with each other.

(4) In my town/city, Black and White people avoid having romantic relationships with each other.

(5) In my town/city, Black and White people avoid having each other as neighbors.

(6) In my town/city, Black and White people avoid shopping in stores with each other.

(7) In my town/city, Black and White people avoid attending events with each other.

(8) In my town/city, Black and White people avoid working with each other.

(9) In my town/city, if Black and White people had to interact with each other, they would end the interaction as soon as possible.

(10) In my town/city, if Black and White people had a choice, they would rather not interact with each other.

(11) In my town/city, if Black and White people can avoid interacting with each other, they do.

Perceived intergroup anxiety. Intergroup anxiety

(1) In my town/city, Black and White people feel nervous about interacting with each other.

(2) In my town/city, Black and White people seem to feel uneasy about interacting with each other.
(3) In my town/city, Black and White people feel tense about interacting with each other.

(4) In my town/city, Black and White people feel bothered about interacting with each other.

Items are rated on a scale from 1 (strongly disagree), 4 (somewhat), and 7 (strongly agree).

\section{Perceived interracial trust.}

(1) In my town/city, Black and White people are basically honest with each other.

(2) In my town/city, Black and White people view each other as trustworthy.

(3) In my town/city, Black and White people view each other as basically good and kind.

(4) In my town/city, Black and White people are trustful of each other.

Respondents were asked to give a score ranging from 1 to 7 , where 1 represented very low trust in others and 7 very high trust.

Seven-point scale $(1=$ not at all, $4=$ somewhat, and $7=$ completely).

\section{Authors' Note}

All data are available for download (http://socialstresslab.wixsite. com/urochester/research).

\section{Declaration of Conflicting Interests}

The author(s) declared no potential conflicts of interest with respect to the research, authorship, and/or publication of this article.

\section{Funding}

The author(s) received no financial support for the research, authorship, and/or publication of this article.

\section{ORCID iD}

Jonathan Gordils (D) https://orcid.org/0000-0001-5055-5918

\section{Supplemental Material}

The supplemental material is available in the online version of the article.

\section{Notes}

1. The analysis did not include a test of the RIGap $\times$ Race interaction because of the low number of Blacks.

2. Although we did not formulate any interaction hypotheses with race, it is possible to imagine that the influence of the RIGap is limited to Blacks and wonder whether we had sufficient power to detect such a fan-shaped RIGap $\times$ Race interaction. A post hoc simulation of $N=10,000$ samples of $N=1,744$ participants revealed that our sample size was appropriately powered (i.e., $\geq$. $80)$ to detect this type of interaction when the size of the RIGap effect was $d \geq .27$ for Blacks (i.e., $f^{2}=.02$; a rather small-sized effect) and $d=0$ for Whites (a null effect). 
3. To test for individual observations that had an outsized impact on the pattern of data, Cook's distance was calculated for all models. One case had a Cook's $D$ of .32 , which was both well above the cutoff of $4 / N$ and higher compared to the other cases (in the model using perceived racial competition as the outcome variable; see Sheather, 2009). This influential case was removed, and results remain the same whether the influential case is in or out of the data set, with the exception that a significant interaction effect predicting perceived racial competition emerges with the influential case included $(\beta=.06[.01, .11], p=.017)$. With this case removed, this interaction effect becomes nonsignificant $(\beta=.04[-.01, .09], p=$ .12 ), suggesting that this effect is not reliable.

4. See Supplemental Materials for ancillary analyses controlling for average ZIP code income.

\section{References}

Allport, G. W. (1954). The nature of prejudice. Reading, MA: Addison-Wesley.

Amodio, D. M. (2009). Intergroup anxiety effects on the control of racial stereotypes: A psychoneuroendocrine analysis. Journal of Experimental Social Psychology, 45, 60-67.

Anier, N., Guimond, S., \& Dambrun, M. (2016). Relative deprivation and gratification elicit prejudice: Research on the V-curve hypothesis. Current Opinion in Psychology, 11, 96-99.

Bertrand, M., Mullainathan, S., \& Shafir, E. (2004). A behavioraleconomics view of poverty. The American Economic Review, 94, 419-423.

Blau, J. R., \& Blau, P. M. (1982). The cost of inequality: Metropolitan structure and violent crime. American Sociological Review, 47, 114-129.

Blau, P. M., \& Golden, R. M. (1986). Metropolitan structure and criminal violence. The Sociological Quarterly, 27, 15-26.

Bobo, L., \& Hutchings, V. L. (1996). Perceptions of racial group competition: Extending Blumer's theory of group position to a multiracial social context. American Sociological Review, 61, 951-972.

Bos, P. A., Terburg, D., \& Van Honk, J. (2010). Testosterone decreases trust in socially naive humans. Proceedings of the National Academy of Sciences, 107, 9991-9995.

Brewer, M. B. (2001). Ingroup identification and intergroup conflict. Social Identity, Intergroup Conflict, and Conflict Reduction, 3, $17-41$.

Brewer, M. B., \& Gaertner, S. L. (2001). Toward reduction of prejudice: Intergroup contact and social categorization. In R. Brown \& S. L. Gaertner (Eds.), Blackwell handbook of social psychology: Intergroup processes (pp. 451-472). Maldon, MA: Blackwell.

Brown, R. (1988). Group processes: Dynamics within and between groups. Cambridge, MA: Basil Blackwell.

Burgess, D. J., Ding, Y., Hargreaves, M., Van Ryn, M., \& Phelan, S. (2008). The association between perceived discrimination and underutilization of needed medical and mental health care in a multi-ethnic community sample. Journal of Health Care for the Poor and Underserved, 19, 894-911.

Burr, J. A., Hartman, J. T., \& Matteson, D. W. (1999). Black suicide in US metropolitan areas: An examination of the racial inequality and social integration-regulation hypotheses. Social Forces, 77, 1049-1080.
Calvo, M. G., \& Dolores Castillo, M. (2001). Selective interpretation in anxiety: Uncertainty for threatening events. Cognition \& Emotion, 15, 299-320.

Carré, J. M., Baird-Rowe, C. D., \& Hariri, A. R. (2014). Testosterone responses to competition predict decreased trust ratings of emotionally neutral faces. Psychoneuroendocrinology, 49, $79-83$.

Cheung, F., \& Lucas, R. E. (2016). Income inequality is associated with stronger social comparison effects: The effect of relative income on life satisfaction. Journal of Personality and Social Psychology, 110, 332.

Clark, R., Coleman, A. P., \& Novak, J. D. (2004). Brief report: Initial psychometric properties of the everyday discrimination scale in black adolescents. Journal of Adolescence, 27, 363-368.

Cramer, A. O., van Ravenzwaaij, D., Matzke, D., Steingroever, H., Wetzels, R., Grasman, R. P., .. Wagenmakers, E. J. (2016). Hidden multiplicity in exploratory multiway ANOVA: Prevalence and remedies. Psychonomic Bulletin \& Review, 23, 640-647.

Crowder, K. D. (2001). Racial stratification in the actuation of mobility expectations: Microlevel impacts of racially restrictive housing markets. Social Forces, 79, 1377-1396.

Diaz-Gimenez, J., Quadrini, V., \& Ríos-Rull, J. V. (1997). Dimensions of inequality: Facts on the US distributions of earnings, income, and wealth. Federal Reserve Bank of Minneapolis. Quarterly Review, 21, 3.

Dressler, W. W., Oths, K. S., \& Gravlee, C. C. (2005). Race and ethnicity in public health research: Models to explain health disparities. Annual Review of Anthropology, 34, 231-252.

Elgar, F. J., Gariépy, G., Torsheim, T., \& Currie, C. (2017). Early-life income inequality and adolescent health and well-being. Social Science \& Medicine, 174, 197-208.

Emerson, M. O., Chai, K. J., \& Yancey, G. (2001). Does race matter in residential segregation? Exploring the preferences of white Americans. American Sociological Review, 66, 922-935.

Festinger, L. (1954). A theory of social comparison processes. Human Relations, 7, 117-140.

Fiske, S. T. (2010). Envy up, scorn down: How comparison divides us. American Psychologist, 65, 698.

Fiske, S. T., Cuddy, A. J., Glick, P., \& Xu, J. (2002). A model of (often mixed) stereotype content: Competence and warmth respectively follow from perceived status and competition. Journal of Personality and Social Psychology, 82, 878.

Gibbons, F. X., Gerrard, M., Cleveland, M. J., Wills, T. A., \& Brody, G. (2004). Perceived discrimination and substance use in African American parents and their children: A panel study. Journal of Personality and Social Psychology, 86, 517.

Gilbert, D. T., Giesler, R. B., \& Morris, K. A. (1995). When comparisons arise. Journal of Personality and Social Psychology, 69, 227.

Gradín, C. (2014). Race and income distribution: Evidence from the USA, Brazil and South Africa. Review of Development Economics, 18, 73-92.

Greenwald, A. G., \& Banaji, M. R. (1995). Implicit social cognition: Attitudes, self-esteem, and stereotypes. Psychological Review, $102,4$. 
Guimond, S., \& Dambrun, M. (2002). When prosperity breeds intergroup hostility: The effects of relative deprivation and relative gratification on prejudice. Personality and Social Psychology Bulletin, 28, 900-912.

Hayes, A. F. (2013). Introduction to mediation, moderation, and conditional process analysis: A regression-based approach. New York, NY: Guilford Press.

Islam, M. R., \& Hewstone, M. (1993). Dimensions of contact as predictors of intergroup anxiety, perceived out-group variability, and out-group attitude: An integrative model. Personality and Social Psychology Bulletin, 19, 700-710.

Jacobs, D., \& Wood, K. (1999). Interracial conflict and interracial homicide: Do political and economic rivalries explain white killings of blacks or black killings of whites? American Journal of Sociology, 105, 157-190.

Jamieson, J. P., Hangen, E. J., Lee, H. Y., \& Yeager, D. S. (2018). Capitalizing on appraisal processes to improve affective responses to social stress. Emotion Review, 10, 30-39.

Jamieson, J. P., Nock, M. K., \& Mendes, W. B. (2012). Mind over matter: Reappraising arousal improves cardiovascular and cognitive responses to stress. Journal of Experimental Psychology: General, 141, 417.

Jaret, C., Reid, L. W., \& Adelman, R. M. (2003). Black-white income inequality and metropolitan socioeconomic structure. Journal of Urban Affairs, 25, 305-334.

Jefferson, A. L., Himali, J. J., Beiser, A. S., Au, R., Massaro, J. M., Seshadri, S., . . Benjamin, E. J. (2010). Cardiac index is associated with brain aging: The Framingham heart study. Circulation, 122, 690-697.

Jost, J. T., Banaji, M. R., \& Nosek, B. A. (2004). A decade of system justification theory: Accumulated evidence of conscious and unconscious bolstering of the status quo. Political Psychology, 25, 881-919.

Kawachi, I., \& Subramanian, S. V. (2014). Income inequality. In L. F. Berkman, I. Kawachi, \& M. M. Glymour (Eds.), Social epidemiology (pp. 126-152). New York, NY: Oxford University Press.

Kessler, R. C., Mickelson, K. D., \& Williams, D. R. (1999). The prevalence, distribution, and mental health correlates of perceived discrimination in the United States. Journal of Health and Social Behavior, 40, 208-230.

Knowles, J., Persico, N., \& Todd, P. (2001). Racial bias in motor vehicle searches: Theory and evidence. Journal of Political Economy, 109, 203-229.

Lackey, S. (2012). It takes two to tango: Stigma consciousness, intergroup anxiety, and avoidance of interactions between Blacks and Whites. New York, NY: St. John's University.

Lee, C., Ayers, S. L., \& Kronenfeld, J. J. (2009). The association between perceived provider discrimination, health care utilization, and health status in racial and ethnic minorities. Ethnicity \& Disease, 19, 330 .

Lochner, K., Kawachi, I., \& Kennedy, B. P. (1999). Social capital: A guide to its measurement. Health \& Place, 5, 259-270.

Major, B. (1994). From social inequality to personal entitlement: The role of social comparisons, legitimacy appraisals, and group membership. In M. P. Zanna (Ed.), Advances in experimental social psychology (Vol. 26, pp. 293-348). San Diego, CA: Academic Press.

Mays, V. M., Cochran, S. D., \& Barnes, N. W. (2007). Race, racebased discrimination, and health outcomes among African Americans. Annual Review of Psychology, 58, 201-225.

McEwen, B. S. (1998). Stress, adaptation, and disease: Allostasis and allostatic load. Annals of the New York Academy of Sciences, 840, $33-44$.

McKernan, S. M., Ratcliffe, C., Steuerle, C. E., \& Zhang, S. (2013). Less than equal: Racial disparities in wealth accumulation. Washington, DC: Urban Institute.

Mendes, W. B., Gray, H. M., Mendoza-Denton, R., Major, B., \& Epel, E. S. (2007). Why egalitarianism might be good for your health: Physiological thriving during stressful intergroup encounters. Psychological Science, 18, 991-998.

Mendes, W. B., \& Park, J. (2014). Neurobiological concomitants of motivational states. In A. J. Elliot (Ed.), Advances in motivation science (Vol. 1, pp. 233-270). Waltham, MA: Academic Press, Elsevier.

Mishra, S., Hing, L. S. S., \& Lalumiere, M. L. (2015). Inequality and risk-taking. Evolutionary Psychology, 13, 1-11. doi:10.1177/ 1474704915596295.

Moscatelli, S., Albarello, F., Prati, F., \& Rubini, M. (2014). Badly off or better off than them? The impact of relative deprivation and relative gratification on intergroup discrimination. Journal of Personality and Social Psychology, 107, 248.

Mummendey, A., Kessler, T., Klink, A., \& Mielke, R. (1999). Strategies to cope with negative social identity: Predictions by social identity theory and relative deprivation theory. Journal of Personality and Social Psychology, 76, 229.

Murayama, K., \& Elliot, A. J. (2012). The competition-performance relation: A meta-analytic review and test of the opposing processes model of competition and performance. Psychological Bulletin, 138, 1035-1070.

National Center for Education Statistics. (2011). The nation's report card: Mathematics 2011 (NCES 2012 458). Washington, DC: Institute of Education Sciences, U.S. Department of Education.

Norton, M. I., \& Ariely, D. (2011). Building a better America-One wealth quintile at a time. Perspectives on Psychological Science, 6, 9-12.

Nunnally, S. C. (2012). Trust in Black America: Race, discrimination, and politics. New York: New York University Press.

Oliver, J. E., \& Mendelberg, T. (2000). Reconsidering the environmental determinants of white racial attitudes. American Journal of Political Science, 44, 574-589.

Page-Gould, E., Mendoza-Denton, R., \& Tropp, L. R. (2008). With a little help from my cross-group friend: Reducing anxiety in intergroup contexts through cross-group friendship. Journal of Personality and Social Psychology, 95, 1080.

Paolini, S., Hewstone, M., Cairns, E., \& Voci, A. (2004). Effects of direct and indirect cross-group friendships on judgments of Catholics and Protestants in Northern Ireland: The mediating role of an anxiety-reduction mechanism. Personality and Social Psychology Bulletin, 30, 770-786. 
Parker, K. F., \& McCall, P. L. (1999). Structural conditions and racial homicide patterns: A look at the multiple disadvantages in urban areas. Criminology, 37, 447-478.

Pascoe, E. A., \& Smart Richman, L. (2009). Perceived discrimination and health: A meta-analytic review. Psychological Bulletin, 135, 531.

Payne, B. K. (2017). The broken ladder: How inequality affects the way we think, live, and die. London, England: Penguin.

Payne, B. K., Brown-Iannuzzi, J. L., \& Hannay, J. W. (2017). Economic inequality increases risk taking. Proceedings of the National Academy of Sciences, 114, 4643-4648.

Perugini, M., Gallucci, M., \& Costantini, G. (2018). A practical primer to power analysis for simple experimental designs. International Review of Social Psychology, 31, 20.

Peterson, R. D., \& Krivo, L. J. (1993). Racial segregation and black urban homicide. Social Forces, 71, 1001-1026.

Phelan, J. C., \& Link, B. G. (2015). Is racism a fundamental cause of inequalities in health? Annual Review of Sociology, 41, 311-330.

Pickett, K. E., \& Wilkinson, R. G. (2015). Income inequality and health: A causal review. Social Science \& Medicine, 128, 316-326.

Prentice, D. A., \& Miller, D. T. (1992). When small effects are impressive. Psychological Bulletin, 112, 160.

Quillian, L. (2002). Why is black-white residential segregation so persistent? Evidence on three theories from migration data. Social Science Research, 31, 197-229.

Rosenthal, R., Rosnow, R. L., \& Rubin, D. B. (2000). Contrasts and effect sizes in behavioral research: A correlational approach. Cambridge, MA: Cambridge University Press.

Schneider, S. M. (2012). Income inequality and its consequences for life satisfaction: What role do social cognitions play? Social Indicators Research, 106, 419-438.

Shapiro, T. M., \& Kenty-Drane, J. L. (2005). The racial wealth gap. African Americans in the US Economy, 175, 177.

Shapiro, T., Meschede, T., \& Osoro, S. (2013). The roots of the widening racial wealth gap: Explaining the black-white economic divide (Research and Policy Brief). Waltham, MA: Institute on Assets and Social Policy. http://iasp.brandeis.edu/pdfs/Author/shapiro-tho mas-m/racialwealthgapbrief.pdf

Shariff, A. F., Wiwad, D., \& Aknin, L. B. (2016). Income mobility breeds tolerance for income inequality: Cross-national and experimental evidence. Perspectives on Psychological Science, 11, 373-380.

Sheather, S. (2009). A modern approach to regression with $R$. New York, NY: Springer Science \& Business Media.

Sherif, M., Harvey, O. J., White, B. J., Hood, W. R., \& Sherif, C. W. (1961). Intergroup cooperation and conflict: The robbers cave experiment. Norman: University of Oklahoma Book Exchange.

Sommet, N., Elliot, A. J., Jamieson, J. P., \& Butera, F. (2018). Income inequality, perceived competitiveness, and approach-avoidance motivation. Journal of Personality. doi: 10.1111/jopy.12432

Stephan, W. G., Boniecki, K. A., Ybarra, O., Bettencourt, A., Ervin, K. S., Jackson, L. A., . . Renfro, C. L. (2002). The role of threats in the racial attitudes of Blacks and Whites. Personality and Social Psychology Bulletin, 28, 1242-1254.
Stephan, W. G., \& Stephan, C. W. (2000). An integrated threat theory of prejudice. In S Oskamp (Ed.), Reducing prejudice and discrimination (pp. 23-45). Mahwah, NJ: Lawrence Erlbaum.

Tajfel, H., \& Turner, J. C. (1979). An integrative theory of intergroup conflict. The social Psychology of Intergroup Relations, 33, 74.

Ten-Velden, F. S., Beersma, B., \& De Dreu, C. K. (2009). Goal expectations meet regulatory focus: How appetitive and aversive competition influence negotiation. Social Cognition, 27, 437-454.

Trawalter, S., Richeson, J. A., \& Shelton, J. N. (2009). Predicting behavior during interracial interactions: A stress and coping approach. Personality and Social Psychology Review, 13, 243-268.

Vanneman, A., Hamilton, L., Anderson, J. B., \& Rahman, T. (2009). Achievement gaps: How Black and White students in public schools perform in mathematics and reading on the national assessment of educational progress (Statistical Analysis Report. NCES 2009-455). Washington, DC: National Center for Education Statistics.

Vanneman, R. D., \& Pettigrew, T. F. (1972). Race and relative deprivation in the urban United States. Race, 13, 461-486.

White, K., Haas, J. S., \& Williams, D. R. (2012). Elucidating the role of place in health care disparities: The example of racial/ ethnic residential segregation. Health Services Research, 47, 1278-1299.

Wilder, D. A., \& Shapiro, P. N. (1989). Role of competition-induced anxiety in limiting the beneficial impact of positive behavior by an out-group member. Journal of Personality and Social Psychology, 56,60 .

Wilkinson, R. G., \& Pickett, K. E. (2006). Income inequality and population health: A review and explanation of the evidence. Social Science \& Medicine, 62, 1768-1784.

Williams, D. R., \& Collins, C. (2001). Racial residential segregation: A fundamental cause of racial disparities in health. Public Health Reports, 116, 404-416.

Williams, D. R., \& Mohammed, S. A. (2009). Discrimination and racial disparities in health: Evidence and needed research. Journal of Behavioral Medicine, 32, 20-47.

Williams, D. R., Yu, Y., Jackson, J. S., \& Anderson, N. B. (1997). Racial differences in physical and mental health: Socioeconomic status, stress and discrimination. Journal of Health Psychology, 2, 335-351.

Yamagishi, T., \& Yamagishi, M. (1994). Trust and commitment in the United States and Japan. Motivation and Emotion, 18, 129-166.

Yeager, D. S., Dahl, R. E., \& Dweck, C. S. (2018). Why interventions to influence adolescent behavior often fail but could succeed. Perspectives on Psychological Science, 13, 101-122.

Yzerbyt, V. Y., Muller, D., Batailler, C., \& Judd, C. M. (2018). New recommendations for testing indirect effects in mediational models: The need to report and test component paths. Journal of Personality and Social Psychology, 115, 929-943.

Zell, E., \& Krizan, Z. (2014). Do people have insight into their abilities? A metasynthesis. Perspectives on Psychological Science, 9, $111-125$ 


\section{Author Biographies}

Jonathan Gordils is a graduate student in the Department of Clinical and Social Science in Psychology at the University of Rochester, Rochester, NY. Currently, he is working on interpersonal conflict, looking at the affective, behavioral, and physiological effects underlying this kind of conflict. Additionally, he is working on how income inequality (including racial income inequality) and resource inequality affect downstream psychological processes.

Nicolas Sommet, $\mathrm{PhD}$, is a junior lecturer in social psychology from University of Lausanne, Lausanne, Switzerland. He works on achievement motivation as well as on the psychological consequences of income inequality.
Andrew J. Elliot is a professor in the Department of Clinical and Social Science in Psychology at the University of Rochester, Rochester, NY. He studies approach and avoidance motivation, particularly in achievement settings.

Jeremy P. Jamieson is an associate professor in the Department of Clinical and Social Science in Psychology at the University of Rochester, Rochester, NY. The primary focus of Dr. Jamieson's work seeks to understand how stress impacts emotions, decisions, and performance. He is particularly interested in using physiological indices of bodily and mental states to delve into the mechanisms underlying the effects of stress on downstream outcomes.

Handling Editor: Dominique Muller 